\title{
BMJ Open Public managers' role in creating workplace social capital (WSC) and its effect on employees' well-being and health: a protocol of a longitudinal cohort study (PUMA-WSC)
}

Signe Pihl-Thingvad, ${ }^{1}$ Sune W Hansen, ${ }^{1}$ Vera Winter (D),${ }^{1,2}$ Michelle S Hansen, ${ }^{1}$ Jurgen Willems ${ }^{1,3}$

To cite: Pihl-Thingvad S, Hansen SW, Winter V, et al. Public managers' role in creating workplace social capital (WSC) and its effect on employees' well-being and health: a protocol of a longitudinal cohort study (PUMA-WSC). BMJ Open 2020;10:e039027. doi:10.1136/ bmjopen-2020-039027

- Prepublication history and additional materials for this paper is available online. To view these files, please visit the journal online (http://dx.doi org/10.1136/bmjopen-2020039027).

Received 01 April 2020 Revised 14 September 2020 Accepted 02 October 2020

Check for updates

(C) Author(s) (or their employer(s)) 2020. Re-use permitted under CC BY-NC. No commercial re-use. See rights and permissions. Published by BMJ.

For numbered affiliations see end of article.

Correspondence to

Dr Vera Winter;

winter@wiwi.uni-wuppertal.de

\section{ABSTRACT}

Introduction Workplace social capital (WSC) has been shown to affect employees' well-being and health, yet it is not clear how public managers can create WSC and which forms of WSC are most important. This study is the first prospective cohort study to examine the relationship between management behaviour, WSC, well-being and sickness absence. It uses a validated and detailed scale on WSC, which can distinguish between bonding, bridging, linking and organisational WSC over time. The study thereby provides rich data giving a much-needed detailed image of how WSC impacts on public employees' well-being and health. Additionally, the study pays special attention to the fact that these relationships can be different for different types of employees and therefore tests a set of relevant employee and context-related variables.

Methods and analysis Project preparations in terms of agreements and data preparation of existing data started in 2019. This prospective cohort study considers and collects organisational data from 2016 to 2025. Annual employee surveys of more than 8000 employees (in a large Danish municipality) will be combined with register data in all years. This generates a unique cohort of public employees in different professions that are traceable over several years. The annual surveys include information on the management behaviour, WSC and employee outcomes. Fine-grained information on sickness absences will be matched for all employees and years under study. Moreover, confounders and the nested nature of the data will be considered.

Ethics and dissemination Approval has been obtained from The Regional Committee on Health Research Ethics from Southern Denmark and from the University of Southern Denmark. The results will be presented at conferences and published in international peer-reviewed journals and in a practice-oriented monography targeted at public managers. The result will furthermore be disseminated to the involved employees through seminars and workshops in the participating organisations.

\section{INTRODUCTION}

A series of challenges related to demographic changes and increased welfare expenses
Strengths and limitations of this study

- The study produces rich data giving a fine-grained image of how workplace social capital impact on public employees' well-being and health.

- The data rely on register based data combined with annual employee surveys of more than 8000 employees (a full population in a large Danish municipality) and cover various aspects of work environment, management and employee outcomes.

- Generalisation to other organisations and countries should only be done with great caution.

- The study represents the initial step on which could become a larger multicentre international research programme involving various municipalities and other public organisations.

cause rising workloads and new work pressures in most western public sectors, which put employees' well-being and health at risk. Therefore, an urgent challenge for public managers today is how to handle the demands while securing a good and healthy work environment for their employees. Research has linked workplace social capital (WSC) to a good psychosocial work environment, ${ }^{1-3}$ employees' health ${ }^{4-7}$ and reduced sickness absence. $^{8-11}$ Therefore, many researchers consider WSC to be a central factor in relation to managing public health. ${ }^{6} 101213$

WSC is defined as a resource inherent in the social relationships (characterised by social trust, reciprocity and cohesion) that enable the social unit to perform collective actions. ${ }^{14-17}$ However, using WSC as an organisational resource to secure employee health places new demands on public managers. Yet, there is a striking gap in the literature on how public managers may use WSC to facilitate a healthy work environment. The main 
objective of Public managers' role in creating workplace social capital (PUMA-WSC) is to explore the relationships between managerial behaviour, WSC and employees' well-being and health.

Research on WSC in public organisations is relatively new, and thorough empirical studies conducted over time are still lacking. ${ }^{18}$ Few studies have examined how WSC affects public employees' well-being and health over time. ${ }^{4811^{19}}$ In a cohort study of Finish public sector employees, Okansen et al show that WSC was a predictor of physician-diagnosed depression and antidepressant treatment. ${ }^{19}$ Török et al find that WSC is a predictor for long-term sickness absence among Danish public employees $^{8}$ and Framke $e t$ al show that higher levels of WSC are correlated with lower level of exhaustion and sleep disturbance in a cohort study of 606 Danish public employees. ${ }^{20}$ Fine-grained theoretical analyses of WSC distinguish between four different types of social relations, namely bonding, bridging, linking and organisational WSC. ${ }^{14} 162122$ Bonding WSC describes the organisational ties between coworkers within a work group, whereas bridging WSC refers to the ties between different groups at the workplace. These two types characterise horizontal relationships at the same hierarchical level in an organisation. On the contrary, linking and organisational WSC characterise the vertical relationships across organisational power and authority gradients. Linking WSC refers to the relationships between the employee and the direct superior, and organisational WSC refers the relationships with the top-level management or the organisation in general. ${ }^{19} 2324$ We may expect that the benefits of the WSC dimensions materialise in different ways. ${ }^{25}$ Bonding WSC, for example, provides the employee with emotional and instrumental support, ${ }^{19}$ which has beneficial effects on self-rated health, ${ }^{5}$ and is an important predictor of sickness absence. ${ }^{26}$ On the other hand linking WSC may define the degree of autonomy in work, which yields employee outcomes such as job satisfaction and commitment. Linking WSC may also entail management attention to, for example, a healthy work-life balance and helps to reduce employee stress. ${ }^{27} 28$

However, the large majority of the empirical studies on WSC fail to distinguish between these four types of WSC. Okansen et al and Framke et al differentiate between vertical and horizontal ties in the organisation. ${ }^{19}{ }^{20}$ Meng et $a l$ is the only study to date that differentiates between all four subtypes of WSC in a sample of private employees, and their results show that the different types of WSC are connected to employee work engagement in different ways, indicating that this distinction is crucial when we consider how WSC impacts employees' well-being and health. ${ }^{24}$ The lack of distinction may seriously affect both the research findings and the work with WSC in practice, as it may produce misleading research results and reduces the chances of pointing out relevant focus areas to the management.

Moreover, there is a striking gap on studies addressing how public managers may handle WSC to facilitate a healthy work environment. In particular, little is known on how public managers' leadership affects WSC. Previous qualitative research indicates a need for different management competencies to deal with the different types of WSC. For example, the work with bonding WSC may require that the manager is able to build a functioning team, bridging WSC requires that the manager supports cross-functional collaborations, while linking WSC requires a leader who is good at translating the organisation's strategy into the units' task solution. ${ }^{14}$ New research (conducted on a smaller sample in Swedish hospital settings) has brought into focus how important leadership is for building up WSC within organisations. Strömgren et al show that different leadership qualities are positively associated with WSC over time. ${ }^{29}$ Yet, there is a lack of research showing how different types of management behaviour (eg, leadership styles, the leader's priorities between different management tasks and the leaders stress-related behaviour) affect the four types of WSC. So far, no studies have investigated the relationships between leadership, WSC and employees' well-being and health. Thus, the research on how leadership may affect WSC and thereby support a healthy work environment needs to be expanded. ${ }^{29}$

Finally, the effects of WSC on health may not be identical for all employees; there can be specific subgroups, for example, related to employees' sociodemographic characteristics (gender, age and migration background), subsectors (eg, education and health) or professions (eg, lawyers, physicians and politicians), for whom WSC has a higher (or lower) impact on well-being and health. New research suggests that employees in an organisation do not necessarily benefit equally from WSC. In particular, recent results indicate that the positive effects of WSC may depend on the employee's gender, ${ }^{371017}$ the type of work they do ${ }^{1730}$ and the profession they represent. ${ }^{11}$ Yet, existing studies have been limited to rather small and specific samples, and the only new and large sample study in the field shows mixed results. ${ }^{8}$ Thus, generalisability is still to be determined. Yet, managers need to account for potentially varying effects on and of WSC within and across different employee groups to avoid creating inequality in their organisational well-being and health initiatives. Thus, a better scientific insight in how WSC plays a different role for different employee groups is needed.

The aim of this study is to explore the relationship between management behaviour, (bonding, bridging, linking and organisational) WSC and employee outcomes (eg, stress, commitment, motivation and sickness absence) in a large Danish municipality. Additionally, these relationships will be further verified within and across various employee subcategories based on relevant classifiers (eg, demographics and professions). The knowledge gained from this study will answer central questions about the role of WSC in relation to employees' well-being and health. This knowledge is of high importance to public managers when they are to develop HR practices that 


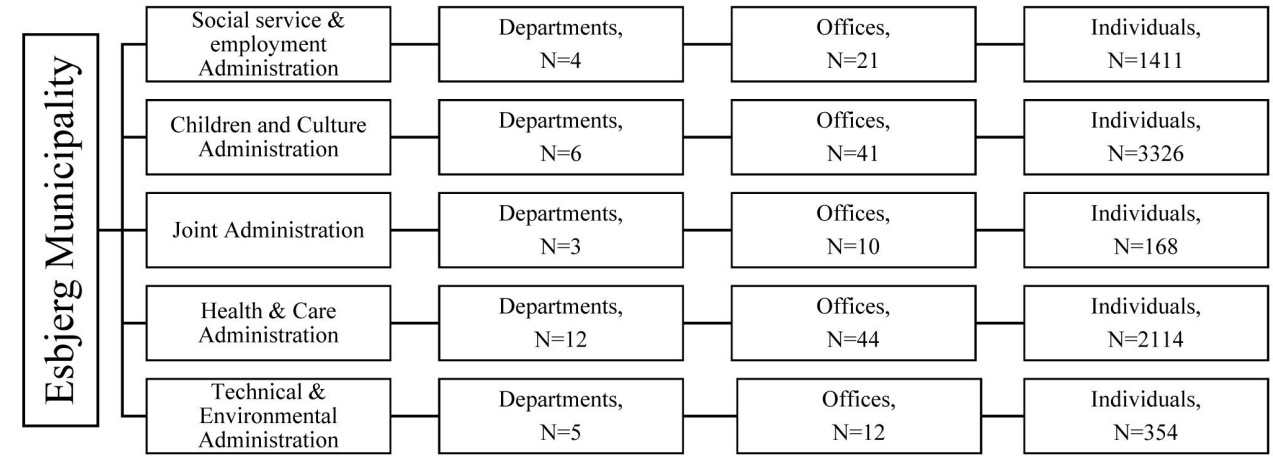

Figure 1 Organisational structure of Esbjerg Municipality 2017. Sample sizes from job satisfaction survey in 2017. Offices consists of up to two additional administrative levels (sections and work units) that are not illustrated in the figure.

support and develop WSC to improve employees' wellbeing and health in the public sector.

\section{METHODS AND ANALYSIS \\ Study design}

The study will be designed as a quantitative longitudinal study on an unbalanced employee panel over a 9-year time period. The main data sources are survey and register data on employees in one municipality. The data are collected by the municipality but need to be prepared and integrated to be useable for research purposes. While representing the main part, the quantitative part will be supplemented by qualitative data analyses on open-ended questions and potentially relevant further data. The design can further be described as a practice-oriented approach, due to the high involvement of the municipality and public entities acting as partners. Nonetheless, the study is driven by research purposes and is expected to contribute to the state-of-the-art knowledge of public management research.

\section{Sample and setting}

The research project is a prospective cohort study of all managers and employees in Esbjerg municipality in the period 2016-2025 (see figure 1 for the organisational structure of the municipality). The municipality represents a multifaceted public context with a broad spectrum of occupations under the same collective regulations (eg, personnel policies and guidelines for management behaviour). Esbjerg municipality is the fifth largest municipality in Denmark and located in southwestern Denmark (detailed key figures can be found in ${ }^{31}$ ). The municipality has more than 8000 employees. The employees make up our target and study population (with a few exceptions, see the appendix for details). The surveys are administered by the municipality and sent out to all employees and managers (see table 1 for the characteristics of the participants in 2017).

Research has pointed out that public managers who are embedded in bureaucratic systems are subject to political and institutional constraints. ${ }^{32} 33$ This is also the case in Esbjerg municipality regarding WSC. The administrative top-level management encourages the managers to put a strategic focus on sickness absence and to use WSC as an important tool in the formal management guidelines. ${ }^{34}$ As in other bureaucratic organisations, the managers' strategic leeway regarding WSC-related decisions and actions is presumably more restricted by standardised rules and procedures than it is for managers in private organisations.

\section{Data collection and integration}

This study gathers and integrates the survey data and combines them with register data on all employees during the existing and future periods of the assessments (from 2016 to 2025). An analysis of the unmatched data (until 2017) shows that the matched and unmatched participants are very similar with respect to gender, age and seniority. The main data sources are briefly described in the following subsections.

Survey on job satisfaction and psychosocial work environment The project data will include job satisfaction surveys conducted in $2017(\mathrm{n}=8643, \mathrm{n}=7373$ yielding a response rate of $85 \%$ ), 2020, 2022 and 2024. The job satisfaction

Table 1 Demographic characteristics of employees participating in job satisfaction survey 2017

\begin{tabular}{lc}
\hline & $\mathbf{2 0 1 7}$ \\
\cline { 2 - 2 } N (\%) & Participants \\
\hline Sex (\%) & $7373(85)$ \\
$\quad$ Women & 81 \\
$\quad$ Men & 19 \\
Has staff responsibility (\%) & \\
$\quad$ Yes & 6 \\
$\quad$ No & 94 \\
Age, years & \\
$\quad$ Mean (SD) & $47(11)$ \\
\hline Seniority, years & \\
$\quad$ Mean (SD) & $10(9)$ \\
\hline
\end{tabular}

2017 Job Satisfaction survey. Age and seniority are missing for one respondent. 
surveys cover all employees (approximately 8000 individuals) and include a series of questions related to the municipality's staff policy as well as a series of researchvalidated questions on employee outcomes and psychosocial work environment, described later.

\section{Survey on management behaviour}

The project will use data on all managers (approximately 400) of a broad variety of public organisations and departments in Esbjerg municipality collected in connection with the municipality's management evaluations $2016(\mathrm{n}=9008 ; \mathrm{n}=7579$ yielding a response rate of $84 \%$ ), 2020, 2022 and 2024. The management evaluation is a 360-degree evaluation comprising the assessment of a manager's behaviour by (a) the manager herself/ himself, (b) his/her superior, (c) a peer manager and (d) subordinate managers and employees. The relationship between management and employees has rarely been studied from the perspectives of both parties and research has yet to shed light on this issue in studies of WSC and employee outcomes. ${ }^{35}$ These data, as well as the possibility to match managers' self-evaluations with evaluations from others for five behavioural categories (see measures) allow for a detailed analysis of the direct effect of leadership behaviour on (the change over time in) WSC, and the resulting influence on sickness absence and perceived well-being of team members. Such analysis will contribute to the understanding of which management behaviours affect WSC and related variables of interest, enabling direct practical recommendations for managers to improve WSC. Moreover, the 360-degree management data structure allows for testing additional effects of selfother agreement for the various combinations with other assessors on management behaviour. ${ }^{36}{ }^{37}$ In this analysis, we will be guided by seminal insights and suggestionsfor example, on the value of polynomial regressions for this type of data-from recent studies with a similar data structure for other Danish municipalities. ${ }^{38}{ }^{39}$ Moreover, by the use of a response surface analysis, ${ }^{37}$ the congruence of self-perception and others' perceptions can be studied in relation to WSC, sickness absence and the manager's own health-related measures. ${ }^{39}$

\section{Register data}

In addition to the above-mentioned survey data, the project will make use of register data, in particular sickness absence (regular sickness absence, absence that falls under the Danish section 56 agreement with chronically sick employees and absence due to work-related injuries) of all employees in Esbjerg municipality. Data on sickness absence are available on a monthly basis, as are data on the number and duration of the employees' sick leave periods. For the job satisfaction surveys in 2017, sickness absence can be matched for $95 \%$ of the participants $(6992$ out of 7373). In addition, register data on gender, age, staff responsibility, section and occupation of each will be used. The data have been collected from Silkeborg Data.

\section{Data integration and timeline}

The extensive sets of quantitative data can be linked, based on unique identifiers on the personal level. We will also account for the hierarchical nature of the data with levels mirroring the organisational structure of the municipality (eg, employees nested in workplace units and nested in administrations). We have been preparing this set-up over the last 2 years, by making agreements with the municipality to get access to their data and by developing a system that allow us to combine the data. Furthermore (as a preparation for the study), we have scrutinised the existing organisational data to see whether they were suitable for the project. In 2019, we started building up the cohort and are now ready to develop it with new data in the years to come. The timeline of the data collection and integration is presented in figure 2.

\section{Measures}

The measures used for this study will be described in the following. The two main predictor variables are managerial behaviour and WSC. The main outcome variables comprise employees' well-being, additional employee outcomes and sickness absence. See the Appendix, for an overview of the items and measures.

\section{Managerial behaviour}

Management evaluations exist for approximately 400 managers at each point of data collection. The

Figure 2 Timeline of the data collection and integration. 
management evaluation questions fall within the five behavioural categories: strategic management, personnel management, professional management, management of finances and operations, and personal management. Under each category the evaluations contain six items inspired by general management literature. ${ }^{40}$ The questions must be answered on a 7-point Likert scale.

In addition, the evaluation contains a question with an assessment of the leader in general (on the same scale as before) and two questions with open response categories, asking about what the manager should do more of and what the manager should begin to do. This part of the management evaluation thus contains a series of qualitative responses, which will be coded and analysed using Nvivo and to be subsequently integrated with the quantitative datasets.

\section{WSC among public employees}

WSC assessments are made by approximately 8000 employees at each point of data collection. The WSC scale has been adapted from a validated questionnaire on WSC from the Danish National Research Centre for the Working Environment. ${ }^{23}$ It comprises 15 items to cover the four dimensions bonding, bridging, linking and organisational WSC. Questions are measured on a 5-point Likert scale.

\section{Well-being and additional outcomes among public employees}

As for WSC, well-being assessments are made by approximately 8000 employees at each point of data collection. Well-being is measured by a four items-stress measure, which has been adapted from Copenhagen Psychosocial Questionnaire Second Version (COPSOQ II). ${ }^{2}{ }^{41}$ Two additional employee outcomes are considered, namely organisational commitment and public service motivation. Organisational commitment is measured by three items and public service motivation is measured by four items. Both question batteries have been validated in international research in the field. ${ }^{42-45}$

\section{Registered sickness absence}

Consistent with international research, sickness absence is measured as the number of days sick per year for each employee and year. In further analyses, we will also use the frequencies of absence (ie, how many times an employee has been absent, irrespective of the duration of each absence) and duration of the employees' sick leave periods (to distinguish between short-term and long-term absence) as additional measures.

\section{Potential confounders}

We will include control variables to ensure that our relationships between variables of interest are not spurious and to reduce heterogeneity in the effects. Potential confounding factors include prevalent health problems, gender, age, staff responsibility, section, occupation and other work environment measures (eg, work demands, work-life balance, offensive behaviours, job satisfaction and ergonomics). We draw on validated measures taken from COPSOQ II and The General Nordic Questionnaire for Psychological and Social Factors at Work.

\section{Statistical analyses and power calculation}

For answering the project's research questions, we will exploit the size and longitudinal structure of the datasets. In order to account for the nested nature of our data (repeated measurements and organisational structure), we will use multilevel models and fixed effects models in different variants (linear models for continuous outcomes, Poisson and negative binomial models for sickness absence).

Besides classical moderation and subgroup analyses, when investigating the uniformity of the effects, instead of predetermining potential moderators, effects could vary with employee characteristics in a way that researchers have not considered. Therefore, data analyses methods that inductively derive employee groups (ie, finite mixture models) will be used to detect any unexpected patterns.

Due to the project's relatively large sample sizes, the statistical tests are generally relatively strong. For example, a post hoc calculation of strength shows a high probability (over 98\%) of demonstrating an overall effect in a traditional multiple linear regression model with 10 predictors with relatively weak effects $\left(f^{2}=0.02 \mathrm{cf}\right.$. the convention of Cohen $^{46}$ a statistical significance of $1 \%$ and a sample size of 2000 (which is a conservative estimate cf. figure 2).

\section{Participant and public involvement}

The project pursues a practice-oriented approach, where public actors are involved as partners in the sense that they provide direct input (eg, influencing the design of the data structure by identifying the relevant level to account for (work group, section, department, organisation and so on) and by expressing their most pressing questions from a managerial point of view). In addition, managers and decision makers in the municipality will receive regular updates on results of the data analysis and will be involved in discussing and explaining the findings.

The project will contribute with highly relevant knowledge targeted to managers about how to increase health and well-being for their employees in the public sector. The findings of this cohort study provide detailed insights into how public managers can create social capital at work and how WSC affects employees' well-being and health, both on a general level, and for various subgroups. The findings are vital for public managers to find ways to increase the most relevant forms of WSC in order to ensure employees' well-being and health, which are ultimately crucial for the quality of public service provision. By creating value from the large amounts of existing data generated in public organisations, the project also paves the way for both high-quality research and more well-founded, data-driven management in the public sector. Lastly, the project's practice-oriented approach strengthens the direct applicability of the research results, while also making them more generalisable. This makes it possible for managers to transfer them to other 
public organisations. To ensure the public involvement, workshops with the managers and employees are held on a regularly basis. During these workshops, preliminary results are presented and discussed with the participants.

\section{ETHICS AND DISSEMINATION}

The study was approved by The Scientific Ethics Committees for the Region of Southern Denmark ${ }^{47}$ (no. 20192000-40) on 25 February 2019 and by the University of Southern Denmark (SDU) under the joint data notification scheme on 10 March 2017, and was transferred to SDUs record, cf. article 30 of General Data Protection Rules (GDPR) on 25 May 2018. Because a part of the data already exists and future data will be collected by Esbjerg Municipality for administrative purposes, the research project builds on proxy consent. Every employee who is part of an employment relationship in a Danish Public organisation permits the organisation to collect and process data about him/her by signing the employment contract. Employees are fully informed that after signing the contract, their information may be used for statistical analyses of scientific and public interest. This is authorised in the Danish Data Protection Regulation and Data Protection Act (Data Protection Act, Act No. 502 of 23 May 2018, Applicable (linking of the different data without consent is also included under $§ 10(1))){ }^{48}$ Consequently, Esbjerg Municipality is the owner of the data and is legally authorised by Danish law to give a proxy consent.

When Esjberg Municipality introduced the GDPR in 2019, they sent out an information form to all employees in the municipality which specified that data can be used for statistical analyses of scientific and public interest (and specifically mentioned the data sets used by PUMA-WSC). Thus, all participants in PUMA-WSC are fully informed about the project. Furthermore, it is voluntary for all employees in Esbjerg Municipality to participate in the different surveys included in PUMA-WSC. Therefore, it is considered as implied consent, when the employees choose to complete the various questionnaires.

Firm collaboration agreements are made between the research team and Esbjerg Municipality which ensure that Esbjerg Municipality will have no access to the integrated datasets processed in PUMA-WSC. Furthermore, it will not be possible to identify any individual employee in the published results from PUMA-WSC, and no results from the project may be used for administrative decisions.

Due to the agreement with Esbjerg municipality, data access is restricted to researchers affiliated with SDU, who have signed the cooperation agreement and code of conduct statement. Hence, public access to this dataset is not possible. The data are stored, processed and analysed according to newest safety and security standards.

\section{DISCUSSION}

Although WSC has been pointed out as an important organisational resource to support employees' well-being and health, research on how managers may handle WSC is sparse. We still lack knowledge of what kind of leadership behaviour supports the development of WSC and, until now, research has not differentiated between the different subtypes of WSC. A better understanding of whether WSC supports well-being and health in specific groups or among employees in an entire organisation is also needed. Existing research has furthermore been criticised for data availability bias in the form of imprecise measurements for WSC and lack of knowledge about the causal mechanisms. ${ }^{49}{ }^{50}$ PUMA-WSC is the first prospective cohort study in the field to use a validated and detailed scale on WSC, which can differentiate between bonding, bridging and linking WSC. Moreover, the study produces rich data that provide a valid foundation for examining the understudied causal mechanisms. Furthermore, it is the first study to integrate detailed management evaluations with self-reported data on WSC, work environment, well-being and registered sickness absence. Thus, the project avoids the prevailing problems in the field with common source bias. ${ }^{50}$ However, using self-reported questionnaires for WSC and employee outcomes (eg, stress and motivation) may risk that the correlations between these constructs are inflated by self-reporting bias. To minimise this risk, our self-reported measures are built on validated scales with sound psychometric properties and robust construct validity. Compared with other existing studies in the field, PUMA-WSC is only the second prospective cohort study following a full population of public employees and their managers (see also ref. 18), yet PUMA-WSC stands out by using new and more detailed data with very high response rates in the different survey waves. Due to the characteristics of the individual data sources, the design makes it possible to link to other Danish high-quality registers (eg, the Danish Register for Evaluation of Marginalisation at the National Labour Market Authority). In doing so, we can answer several understudied questions on public health in future research projects. Hence, PUMA-WSC has a very strong design to follow leadership behaviour, WSC and employee outcomes over time among a specific cohort of public employees. However, generalisability to private organisations (both for-profit and non-profit) and other countries cannot be validated. Still, PUMA-WSC represents the initial step that could become a larger multicentre international research programme involving various municipalities and other public and private organisations. Finally, another significant advantage of PUMA-WSC is the close interaction with HR practitioners and other non-academic stakeholders to solve highly salient organisational problems with public employees' well-being and health. PUMA-WSC creates value from a large amount of existing organisational data generated in the public administrations but rarely used for analytical purposes. Findings of this cohort study provide insights into how public managers can create WSC and how 
WSC affects employees' well-being and health, both on a general level, for different types of WSC and for various subgroups. Through an ongoing dissemination effort and dialogue with the involved partners, PUMA-WSC provides public managers with evidence-based suggestions for best practice regarding how to design effective organisational WSC initiatives and ensure employees' well-being and health, which are ultimately crucial for the quality of public service.

\section{Author affiliations}

${ }^{1}$ Department of Political Science and Public Management, University of Southern Denmark, Odense, Denmark

${ }^{2}$ Department of Health Care Management, Schumpeter School of Business and Economics, University of Wuppertal, Wuppertal, Germany

${ }^{3}$ Institute for Public Management und Governance, Department of Management, WU Wien, Wien, Austria

Acknowledgements The authors would like to thank all employees and managers in Esbjerg municipality especially Birgitte Stenderup, Peter Hillerup, Marie Wullf Hansen and Thomas Rødgaard Poulsen for collaborating on this project and providing important information on the data, as well as relevant feedback and inputs to the project. They would also like to thank their colleagues at Department of Political Science and Public management at University of Southern Denmark and all the members of the projects' Advisory board.

Contributors SP-T leads the study and is responsible for the overall study design and collaboration agreements with Esbjerg municipality. SP-T and SWH are responsible for collecting, handling, integrating and quality-assuring the data sources. SWH is the projects' overall data-manager. SP-T wrote the funding application with help from MSH, which was the intellectual foundation for this article. VW and SP-T wrote the first draft of this article and MSH, SWH and JW critically reviewed and approved the final version of the manuscript. All authors have provided academic feedback on all sections of the manuscript.

Funding The project was funded by The Danish Working Environment Research Fund (J.nr. 20185100800). The research protocol was reviewed by both a scientific and a strategic work environmental research committee in the autumn 2018. However, the fund did not influence the final study design, nor will it influence the future work with the data, analyses or publications.

Competing interests None declared.

Patient consent for publication Not required.

Provenance and peer review Not commissioned; externally peer reviewed.

Supplemental material This content has been supplied by the author(s). It has not been vetted by BMJ Publishing Group Limited (BMJ) and may not have been peer-reviewed. Any opinions or recommendations discussed are solely those of the author(s) and are not endorsed by BMJ. BMJ disclaims all liability and responsibility arising from any reliance placed on the content. Where the content includes any translated material, BMJ does not warrant the accuracy and reliability of the translations (including but not limited to local regulations, clinical guidelines, terminology, drug names and drug dosages), and is not responsible for any error and/or omissions arising from translation and adaptation or otherwise.

Open access This is an open access article distributed in accordance with the Creative Commons Attribution Non Commercial (CC BY-NC 4.0) license, which permits others to distribute, remix, adapt, build upon this work non-commercially, and license their derivative works on different terms, provided the original work is properly cited, appropriate credit is given, any changes made indicated, and the use is non-commercial. See: http://creativecommons.org/licenses/by-nc/4.0/.

\section{ORCID iD}

Vera Winter http://orcid.org/0000-0001-7087-2400

\section{REFERENCES}

1 Hasle P, Møller N. From conflict to shared development: social capital in a Tayloristic environment. Economic Indust Democ 2007;28:401-29.
2 Pejtersen JH, Kristensen TS, Borg V, et al. The second version of the Copenhagen psychosocial questionnaire. Scand J Public Health 2010;38:8-24.

3 Boyas J, Wind LH. Employment-based social capital, job stress, and employee burnout: a public child welfare employee structural model. Child Youth Serv Rev 2010;32:380-8.

4 Liukkonen V, Virtanen P, Kivimäki M, et al. Social capital in working life and the health of employees. Soc Sci Med 2004;59:2447-58.

5 Murayama H, Fujiwara Y, Kawachi I. Social capital and health: a review of prospective multilevel studies. J Epidemiol 2012;22:179-87.

6 Løkke A-K. Social capital and health and job related outcomes: the case of a large municipality. Intl $\mathrm{J}$ of Workplace Health Mgt 2016;9:17-31.

7 Gilbert KL, Quinn SC, Goodman RM, et al. A meta-analysis of social capital and health: a case for needed research. $J$ Health Psychol 2013;18:1385-99.

8 Török E, Clark AJ, Jensen JH, et al. Work-unit social capital and long-term sickness absence: a prospective cohort study of 32053 Hospital employees. Occup Environ Med 2018;75:623-9.

9 Hansen A-SK, Madsen IEH, Thorsen SV, et al. Does workplace social capital protect against long-term sickness absence? linking workplace aggregated social capital to sickness absence registry data. Scand J Public Health 2018;46:290-6.

10 Kiss P, De Meester M, Kristensen TS, et al. Relationships of organizational social capital with the presence of 'gossip and slander,' 'quarrels and conflicts,' sick leave, and poor work ability in nursing homes. Int Arch Occup Environ Health 2014;87:929-36.

11 Rugulies R, Hasle P, Pejtersen JH, et al. Workplace social capital and risk of long-term sickness absence. are associations modified by occupational grade? Eur J Public Health 2016;26:328-33.

12 Tummers LLG, Bekkers V, Vink E, et al. Coping during public service delivery: a conceptualization and systematic review of the literature. JOPART 2015;25:1099-126.

13 Tummers L, Bekkers V, Steijn B. Policy alienation of public professionals: application in a new public management context. Public Management Review 2009;11:685-706.

14 Hasle P, Thoft E, Olesen KG. Ledelse Med social kapital. Kopenhagen: L \& R Business, 2010.

15 Kawachi I, Berkman L. Social cohesion, social capital, and health. Social Epidemiol 2000;174:190.

16 Putnam RD. Bowling alone: the collapse and revival of American community. New York, NY: Simon and Schuster, 2001.

17 Oksanen T, Kawachi I, Kouvonen A, et al. Workplace determinants of social capital: cross-sectional and longitudinal evidence from a Finnish cohort study. PLoS One 2013;8:e65846-7.

18 Hvidtfeldt UA, Bjorner JB, Jensen JH, et al. Cohort profile: the well-being in hospital employees (whale) study. Int $J$ Epidemiol 2017;46:1758-9.

19 Oksanen T, Kouvonen A, Vahtera J, et al. Prospective study of workplace social capital and depression: are vertical and horizontal components equally important? J Epidemiol Community Health 2010;64:684-9.

20 Framke E, Sørensen OH, Pedersen J, et al. The association of vertical and horizontal workplace social capital with employees' job satisfaction, exhaustion and sleep disturbances: a prospective study. Int Arch Occup Environ Health 2019;92:883-90.

21 Woolcock M. Social capital and economic development: toward a theoretical synthesis and policy framework. Theory Soc 1998;27:151-208.

22 Olesen KG, Thoft E, Hasle P, et al. Virksomhedens sociale kapital. Hvidbog. Kopenhagen: Det Nationale Forskningscenter for Arbejdsmiljø (NFA) \& Arbejdsmiljørådet, 2008.

23 Borg V, Mateu N, Clausen T. Udvikling AF en NY metode TIL undersøgelse AF social kapital pă arbejdspladsen Dokumentationsrapport. Report, 2014.

24 Meng A, Clausen T, Borg V. The association between team-level social capital and individual-level work engagement: differences between subtypes of social capital and the impact of intra-team agreement. Scand J Psychol 2018;59:198-205.

25 Kroll A, DeHart-Davis L, Vogel D. Mechanisms of social capital in organizations: how team cognition influences employee commitment and engagement. Am Rev Public Admin 2019;49:777-91.

26 Beemsterboer W, Stewart R, Groothoff J, et al. A literature review on sick leave determinants (1984-2004). Int J Occup Med Environ Health 2009;22:169-79.

27 Caillier JG. The impact of high-quality workplace relationships in public organizations. Public Adm 2017;95:638-53.

28 Jay K, Andersen LL. Can high social capital at the workplace buffer against stress and musculoskeletal pain?: cross-sectional study. Medicine 2018;97:e0124. 
29 Strömgren M, Eriksson A, Ahlstrom L, et al. Leadership quality: a factor important for social capital in healthcare organizations. $J$ Health Organ Manag 2017;31:175-91.

30 Oksanen T, Kouvonen A, Kivimäki M, et al. Social capital at work as a predictor of employee health: multilevel evidence from work units in Finland. Soc Sci Med 2008;66:637-49.

31 Region Syddanmark Regional Udvikling. Kontur 2019 for Esbjerg Kommune ER udgivet AF region Syddanmark, 2019.

32 Rainey HG, Cook M. Understanding and managing public organizations. San Francisco: Jossey-Bass, 2014.

33 P't H, Tummers L. Understanding public leadership. London: Red Globe Press; Macmillan International Higher Education, 2019.

34 Kommune E. Strategi for ledelse 2020Esbjerg Kommune. Strategi for ledelse, 2020.

35 Borg V, Andersen MF. Social kapital på arbejdspladsen. Rapport 1 en NY syntese AF begrebet social kapital på arbejdspladsen. Report 2017.

36 Fleenor JW, Smither JW, Atwater LE, et al. Self-other rating agreement in leadership: a review. Leadersh Q 2010;21:1005-34.

37 Humberg S, Nestler S, Back MD. Response surface analysis in personality and social psychology: checklist and clarifications for the case of congruence hypotheses. Soc Psychol Personal Sci 2019;10:409-19.

38 Løkke A-K, Krøtel SML. Performance evaluations of leadership quality and public sector leaders' absenteeism. Public Management Review 2020;22:96-117.

39 Løkke Nielsen A-K. Determinants of absenteeism in public organizations: a unit-level analysis of work absence in a large Danish municipality. Inter J Human Res Manage 2008;19:1330-48.

40 Yukl GA. Leadership in organizations. 8th edn. Harlow: Pearson Education, 2013.
41 Bjorner JB, Pejtersen JH. Evaluating construct validity of the second version of the Copenhagen psychosocial questionnaire through analysis of differential item functioning and differential item effect. Scand J Public Health 2010;38:90-105.

42 Jacobsen CB, Hvitved J, Andersen LB. Command and motivation: how the perception of external interventions relates to intrinsic motivation and public service motivation. Public Adm 2014;92:790-806.

43 Perry JL. Measuring public service motivation: an assessment of construct reliability and validity. J Public Admin Res Theory 1996;6:5-22.

44 Mowday RT, Steers RM, Porter LW. The measurement of organizational commitment. J Vocat Behav 1979;14:224-47.

45 Wännström I, Peterson U, Asberg M, et al. Psychometric properties of scales in the general Nordic questionnaire for psychological and social factors at work (QPs): confirmatory factor analysis and prediction of certified long-term sickness absence. Scand J Psychol 2009;50:231-44.

46 Cohen J. Statistical power analysis for the behavioral sciences. Mahwah, NJ: Lawrence Erlbaum Associates, 1988.

47 Committee System on Biomedical Research Ethics. Guidelines about notification etc. of a biomedical research project to the Comittee system on Bioedical research ethics, 2011.

48 The Danish Data Protection Agency. The data protection act, 2018

49 Kouvonen A, Kivimäki M, Vahtera J, et al. Psychometric evaluation of a short measure of social capital at work. BMC Public Health 2006;6:251.

50 de $\mathrm{CB}$, Clays $\mathrm{E}$, Janssens $\mathrm{H}$, et al. Health behaviours as a mechanism in the prospective relation between workplace reciprocity and absenteeism: a bridge too far? PLoS One 2015;10:1-13. 